\title{
Role of Chemotherapy in Malignant Bone Tumors
}

\author{
George Romany ${ }^{\mathrm{a}}$, Galal El Din Kazem ${ }^{\mathrm{b}}$, Mohamed A. Meselhy ${ }^{\mathrm{b}}$, Mahmoud I. Kandil ${ }^{b}$
}

a

a Department of orthopedic surgery, Alexandria police hospital, Egypt. ${ }^{\mathrm{b}}$ Department of orthopedic surgery, Faculty of Medicine Benha University, Egypt

Correspondence to: George Romany Department of orthopedic surgery, Alexandria police hospital, Egypt

\section{Email:}

georgeromany78@gmail.com

Received: 15 December 2019

Accepted: 14 August 2021

\begin{abstract}
The purpose of this study was to evaluate the functional and radiological outcome various chemotherapy treatment modalities regarding Malignant Bone tumors. A systematic review was completed. Medline, EMBASE, Pub Med and the Cochrane Central Registry of Controlled Trials (CENTRAL) were searched from January 2009 to January2019. Methods: 23 inclusion studies that described the role of different chemotherapeutic regimens in treatment of different types of malignant bone tumors, from which there were 14 prospective phase 2 trial studies, 2 prospective phase 1 studies, 2 prospective phase 3 studies, while there were 5 retrospective studies. The onset of patients ranges from 15 to $40 \mathrm{ys}$ in 10 studies, more than 40 ys in 2 studies, while no available date in 11 studies. The number of patients included in those studies ranges from 14 to 100 patients in 12 studies, from 100 to 200 patients in 1 study, while there were 10 studies that included more
\end{abstract} than 200 patients. The median follow up period used to obtain results ranges from 1.5 to 25 ys in 12 studies, less than a year in 2 studies, while no available date in 9 studies. Disease free survival rate ranges from $<50 \%$ in 7 studies, $>50 \%$ in 12 studies, while no available date on 4 studies. Overall survival rate ranges from $<50 \%$ in 10 studies, , $>50 \%$ in 8 studies, while no available data on 5 studies. Most of studies that had $>50 \%$ in the overall survival rate and disease free survival rate used neoadjuvant and adjuvant chemotherapy regimen as a part of treatment of non-metastatic Ewing and osteosarcoma. While most of studies that had $<50 \%$ overall survival rate was due to the metastatic or advanced stage of the sarcomas on which those studies were done. For newly diagnosed osteosarcoma in $<40$ ys pts, neoadjuvant H.D.IFO+ADM+CDDP + surgery + adjuvant chemo (H.D.M.T), is associated with very good results (the 5 year event free survival rate is $83 \%$,the 5 year overall survival rate is $98 \%$ ). In 
high grade osteosarcoma, adding IFO to MTX, CDP, and ADM from the preoperative phase does not improve the good responder rate and increases hematologic toxicity. IFO should only be considered in patients who have a poor histologic response to MTX, CDP, and ADM. Patients with high-grade, localized osteosarcoma who received adjuvant chemotherapy after undergoing definitive surgical resection had a statistically significant benefit in disease-free and overall survival that was maintained through 25 years. Tumor necrosis after just 1 cycle of neoadjuvant chemotherapy and radiation was predictive of overall survival and disease-free survival in patients who received adjuvant chemotherapy.

The keywords: 'malignant bone tumor', Bone sarcoma and 'chemotherapy'

\section{Introduction:}

In the United States, it is estimated that approximately 3300 primary malignant bone tumors (excluding malignancies arising in the bone marrow) are diagnosed annually, and approximately half as many deaths result [1]

Adolescents with a bone tumor had consistently lower scores on quality of life as compared to healthy peers. Significantly on domains: physical well-being, autonomy, social support and school environment [2]

For many of the tumors, most not ably osteosarcoma and the Ewing sarcoma, remarkable progress in surgical techniques and multidisciplinary management over the last 40 years has resulted in significant improvements in the likelihood of cure and limb salvage [3].
Malignant bone tumors represent a small percentage of cancers nationwide and also are much less common than malignant softtissue tumors. The rarity of the condition makes it imperative that orthopedic surgeons in non-oncologic practices are able to recognizethesymptomsthatsuggestapossibleb onymalignancytoavoidinappropriate or delayed treatment [4]

Primary malignant bone tumors are uncommon but are a significant cause of cancer morbidity and mortality, especially among young people. Although relatively rare in childhood, primary malignant bone tumors represent the sixth most common neoplasm in children, while in adolescents and young adults, they are the third most frequent, exceeded only by leukemias and lymphomas [4]. 
The most common primary malignant bone tumors, osteosarcoma and Ewing's sarcoma, occur in childhood.

Chondrosarcoma occurs more frequently in older adults. Rare tumors such as chordoma and adamantinoma have anatomic predilections for the sacrum and tibia ,respectively . The primary symptom of a patient with a malignant bone tumor is pain, which often occurs at rest or at night [4]

The biopsy can be an image-guided needle biopsy or an open incisional biopsy. Knowledge of specific tumor characteristics and treatment options for osteosarcoma, Ewing's sarcoma, chondrosarcoma, malignant fibrous histiocytoma, chordoma, and adamantinoma is important. Patients with osteosarcoma and resectable Ewing's sarcoma are treated with chemotherapy followed by surgical resection. Secondary sarcomas can occur in previously benign bone lesions and require aggressive treatment.

Specific techniques are available for the resection of malignant bone tumors from the Upper extremities, lower extremities, pelvis, and spine. Reconstruction options include the use of allografts, mega prostheses, and vascularized autografts [4]
Chemotherapy has had a major impact in malignant bone tumors. In osteosarcoma, metastasis-free survival has been achieved in approximately 50 to 75 per cent of patients [4]

Additional improvement based on the altered pattern of pulmonary metastases has also been reported. Preoperative chemotherapy has facilitated surgical resection of the primary tumor. The effects on the primary tumor may be utilized as a predictive factor and to design postoperative adjuvant therapy. Similar results have been achieved

In Ewing's sarcoma the survival rates is in the vicinity of 50 to 80 percent. The interaction of chemotherapy with radiation has augmented the ability to achieve local control of the primary tumor. The tumoricidal properties of chemotherapy in destroying micrometastases may possibly also contribute to local control. Finally, initial treatment with chemotherapy may yield a complete response and facilitate definitive surgical treatment of the primary tumor. This may eliminate the need for radiation therapy and its delayed consequences [4] 
High-dose chemotherapy and hematopoietic support can produce long-term, disease- free remissions in selected patients with metastatic breast cancer. Occult bone marrow involvement may contribute to late relapse.[4]

Current chemotherapy regimens include doxorubicin, high dose methotrexate, cisplatin and sometimes ifosfamide. This multi-drug approach yields survival rates of approximately $70 \%$ in those patients with no evidence of metastasis at diagnosis. [4]

Induction chemotherapy significantly decreased bone marrow contamination as detected by flow cytometry and cytology in patients with breast cancer. The detection of immunostained cells in the bone marrow did not predict for relapse or overall survival. [4]

The use of multi-agent chemotherapy combined with aggressive surgery has improved the long-term survival in osteosarcoma patients to approximately 60 \%. [7] Neo-adjuvant chemotherapy resulted in higher survival rates. [4]

Bone is a common site for malignant involvement. It is a major source of morbidity, and half of patients with bone involvement develop skeletal-related events such as pathological fractures or cord compression requiring surgery and/or radiation. Skeletal involvement also increases mortality, as pathologic fractures increase the risk of dying by $20-40 \%$. [4]

\section{Materials and Methods}

\section{Search Strategy and Eligibility:}

A systematic literature review was performed to identify all papers relevant to the study objectives. Searches will be performed in the MEDLINE ,EMBASE ,Life Science Citations, PubMed (http://www.ncbi.nlm.nih.gov/sites/entrez/), Google Scholar (http://scholar.google.it/), CINAHL

(http://www.ebscohost.com/cinahl/),

Cochrane Central Register of Controlled Trials databases through 2017 0(ht0tp://www.thecochranelibrary.com/view /0/index.html) and Embase Biomedical (http://www.embase.com/) Databases were accessed to search studies with no limits set during research A literature search was performed using combinations of keywords 'malignant bone tumor', Bone sarcoma and 'chemotherapy' with no limit regarding the year of publication. 


\section{Inclusion Criteria:}

- Clinical human studies.

- Clinical studies with at least 6 months of follow up.

- Skeletally mature population with malignant bone tumors.

- Clinical studies within last 13years only.

\section{Exclusion Criteria:}

- Non-human studies.

- Cadaveric studies.

- Skeletal prematurity.

- Reviews, commentaries and general discussion papers not presenting data on impacts.

\section{Study selection and data extraction:}

Two independent reviewers first screened the study titles and abstracts for eligibility. The full text of the trials potentially meeting the eligibility criteria were reviewed to decide the final inclusion. Then, investigators independently extracted information,

including the lead author, publication year, randomization methods, participant number, patient characteristics (number, age and cancer type), follow-up time, all outcome measures (event free survival rate and overall survival rate). Discrepancies were resolved by consensus after discussion between the two reviewers.

\section{Results}

The literatures each identified 1210 abstracts).Of these, 936 were excluded during abstract review and 274 proceeded to full text review. During full-text review, an additional 8studies were excluded. A total of 23 studies met the inclusion criteria when assessed during full-text review and were included in the present systematic review. Hand-search in the references ofthe 23 included studies identified on additional articles [7-21].

\section{Stat method:}

The collected data presented as suitable tables. Quantitative data summarized as mean \pm SD and qualitative data as frequency and percentage. Analysis of data was performed by the aid of software package of SPSS using Suitable statistical tests. 


\begin{tabular}{|c|c|c|c|c|c|c|}
\hline No & Study & Intervention & No of Pts & $\operatorname{Age}(\mathbf{y})$ & Cancer & $\begin{array}{l}\text { Fu( } \\
\mathbf{y})\end{array}$ \\
\hline 1 & Berntha. ,et al.(7) & $\begin{array}{l}\text { Adju.Chemo or observation } \\
\text { After Surg.resection }\end{array}$ & $\begin{array}{c}59 \\
\text { Of Chemother }\end{array}$ & dpy in Ma & $\begin{array}{l}\text { H.G.O.S } \\
\text { alignant Bone Tumors, } 2021\end{array}$ & 25 \\
\hline 2 & Bianchi, et al.(18) & $\begin{array}{l}\text { Electrochemotherapy } \\
\text { (IV belomycin followed by } \\
\text { electroporation ) }\end{array}$ & 29 & 60 & Bonemetastases & $\begin{array}{l}\text { Half a } \\
\text { year }\end{array}$ \\
\hline 3 & Boye,et al. (8) & $\begin{array}{l}\text { Neo adju.chemo } \\
\text { (MTX,IFO,CDDP,ADM) and } \\
\text { adjuv.chemo } \\
\text { (HDChemo OF } \\
\text { E,ADM,C+Stem cell rescue) }\end{array}$ & 71 & & Metastatic OS & $>5$ \\
\hline 4 & Choy ,.et al. (15) & $\begin{array}{l}\text { Post operative Olaparib tablets+PARP } \\
\text { inhibitors } \\
\text { After prior standard chemo. }\end{array}$ & 22 & 20 & $\begin{array}{l}\text { ES (refractory } \\
\text { metastatic ) }\end{array}$ & $<1$ \\
\hline 5 & Ebb,et al.(9) & $\begin{array}{l}\text { Targeted therapy } \\
\text { Trastuzumab+Standard } \\
\text { chemo(CDDP+ADM+MTX+IFO+E) }\end{array}$ & 96 & & metastatic OS,HER2-positive & $>2.5$ \\
\hline 6 & Ferrari11,et al. (18) & Neoadjuv.(VACAc-IE regimen & 300 & 15 & ES & 5 \\
\hline 7 & Ferrari12,et al. (12) & $\begin{array}{l}\text { Neo adjuv chemo } \\
(\mathrm{HDMT}+\mathrm{CDDP}+\mathrm{A}+\mathrm{IFO}) \text { for } 44 \\
\text { ws }(\text { Arm } \mathrm{A}) \text { or } 34 \mathrm{ws}(\text { Arm } \mathrm{B})\end{array}$ & 246 & $<40$ & OS & 5.5 \\
\hline 8 & Ferrari18,et al.(10) & Neoadjuv (HDMT+CDDP+IFO+ADM) & 218 & $>40$ & HGOS & 4 \\
\hline 9 & $\begin{array}{l}\text { Gaspar,et al. } \\
(14)\end{array}$ & $\begin{array}{l}\text { For IR or SR tumors } \\
\text { (IE) after } 3 \text { courses of ADM+CDDP } \\
\text { ForHR: busulfan,melphalan added }\end{array}$ & 214 & & ES(Residual ) & \\
\hline 10 & $\begin{array}{l}\text { Granow.,et al. } \\
(19\end{array}$ & $\begin{array}{l}\text { VDC/IE over } 48 \text { weeks or VDC/IE over } \\
30 \text { weeks. }\end{array}$ & 478 & & $\begin{array}{l}\text { nonmetastatic ESFT of bone or } \\
\text { soft tissue }\end{array}$ & \\
\hline 11 & Han,K.,et al.(15) & $\begin{array}{c}\text { (VDC/IE) } 1^{\text {st }} \text { line } \\
(\mathrm{HCPT})+(\mathrm{CTX}) \text { as second-line }\end{array}$ & 27 & & Advanced.E.S & \\
\hline 12 & $\begin{array}{l}\text { Iwamot,et al. } \\
\text { (11) }\end{array}$ & $\begin{array}{l}\text { Neoadjuva.chemo } \\
\text { (HD.MTX,CDDP,ADR),+IO }\end{array}$ & 113 & & OS & \\
\hline 13 & $\begin{array}{l}\text { Kudawa.,et al. } \\
(15)\end{array}$ & $\begin{array}{l}\text { Neoadjuv(H.D.IFO } \\
\text {,ADM,CDDP) And adjuv Two cycles } \\
\text { CDDP+H.D.M.T +Surgery }\end{array}$ & 40 & $<40$ & non- metastatic OS & 9.5 \\
\hline 14 & Laux,et al.(12") & Neoadjuvant chemotherapy & 14 & 19 & OS & \\
\hline 15 & Machak.,et al. (22) & $\begin{array}{l}\text { neoadjuvant chemotherapy } \\
\text { of ICE or ICA }\end{array}$ & & 20 & Relapsed OS & 1.5 \\
\hline 16 & Marina., et al. (28) & Adjuv.MAP/IE versus MAP regimen & 618 & & $\begin{array}{l}\text { HGOS(poor response to } \\
\text { preop.Chem }\end{array}$ & 5 \\
\hline 113 & $\begin{array}{l}\text { Meazza } \\
\text {, et al. } \\
(18)\end{array}$ & $\begin{array}{l}\text { Immunotherapy } \\
\text { (IL2+LAK infusion) added to standard } \\
\text { chemo } \\
\text { (HDMT, ADM, CDDP, IFO) }\end{array}$ & 35 & $<18$ & 1RY Metasttic OS & 10.5 \\
\hline 18 & $\begin{array}{l}\text { Mora .,et al. } \\
(20)\end{array}$ & $\begin{array}{l}\text { Neoadjuv.Chemo( GD regimen>> } \\
\text { gemcitabine and docetaxel) }\end{array}$ & 43 & $<40$ & ES & 3.5 \\
\hline
\end{tabular}




\begin{tabular}{|c|c|c|c|c|}
\hline $\mathrm{NO}$ & Study & $\begin{array}{l}\text { Disease- free } \\
\text { rate }\end{array}$ & Overall survival rate at 25 years & Additional comment \\
\hline 1 & $\begin{array}{l}\text { Bernthal, et al. } \\
\text { (7) }\end{array}$ & $\begin{array}{l}28 \% \text { for } \\
\text { adjuvant } \\
\text { chemotherapy }\end{array}$ & $38 \%$ & $\begin{array}{l}\text { Tumor necrosis }>90 \% \\
\text { Statistically significant after } \\
\text { single round of adjuvant } \\
\text { chemo }\end{array}$ \\
\hline 2 & Bianchi., et al.(19) & & & \\
\hline 3 & Boye.,et al. (8) & $27 \%$ & $31 \%$. & \\
\hline 4 & Choy ., et al (15) & & & \\
\hline 5 & Ebb, et al(9) & -) & $\begin{array}{l}\text { In HER2 overexpression treated with } \\
\text { chemo.+ } \\
\text { trastuzumab was } 59 \% \text {. } \\
\text { For HER2 overexpression, treated with } \\
\text { chemotherapy alone,52\% }\end{array}$ & \\
\hline 6 & Ferrari.,et al. 2018(10) & $\begin{array}{l}66 \% \text { in localized dis } \\
22 \% \text { in metastasis }\end{array}$ & $\begin{array}{l}29 \% \text { in localized dis } \\
70 \% \text { for extremity } \\
73 \% \text { for craniofacial locations }\end{array}$ & $\begin{array}{l}\text { Tumor necrosis }>90 \text { in } 21 \% \text { of } \\
\text { cases }\end{array}$ \\
\hline 7 & $\begin{array}{l}\text { Ferrari ., et al. } \\
(2012) .(12)\end{array}$ & $\begin{array}{l}64 \% \text { in arm } \mathrm{A}(44 \mathrm{ws}) \\
55 \% \text { in } \operatorname{arm~} \mathrm{B} . \\
(34 \mathrm{ws})\end{array}$ & $74 \%$ in $\operatorname{arm} \mathrm{A}, \mathrm{B}$. & Tumor necrosis $>90 \%$ good in \\
\hline 8 & $\begin{array}{l}\text { Ferrari ., et al. (2011). } \\
(18)\end{array}$ & $69 \%$ & $75 \%$ & \\
\hline
\end{tabular}




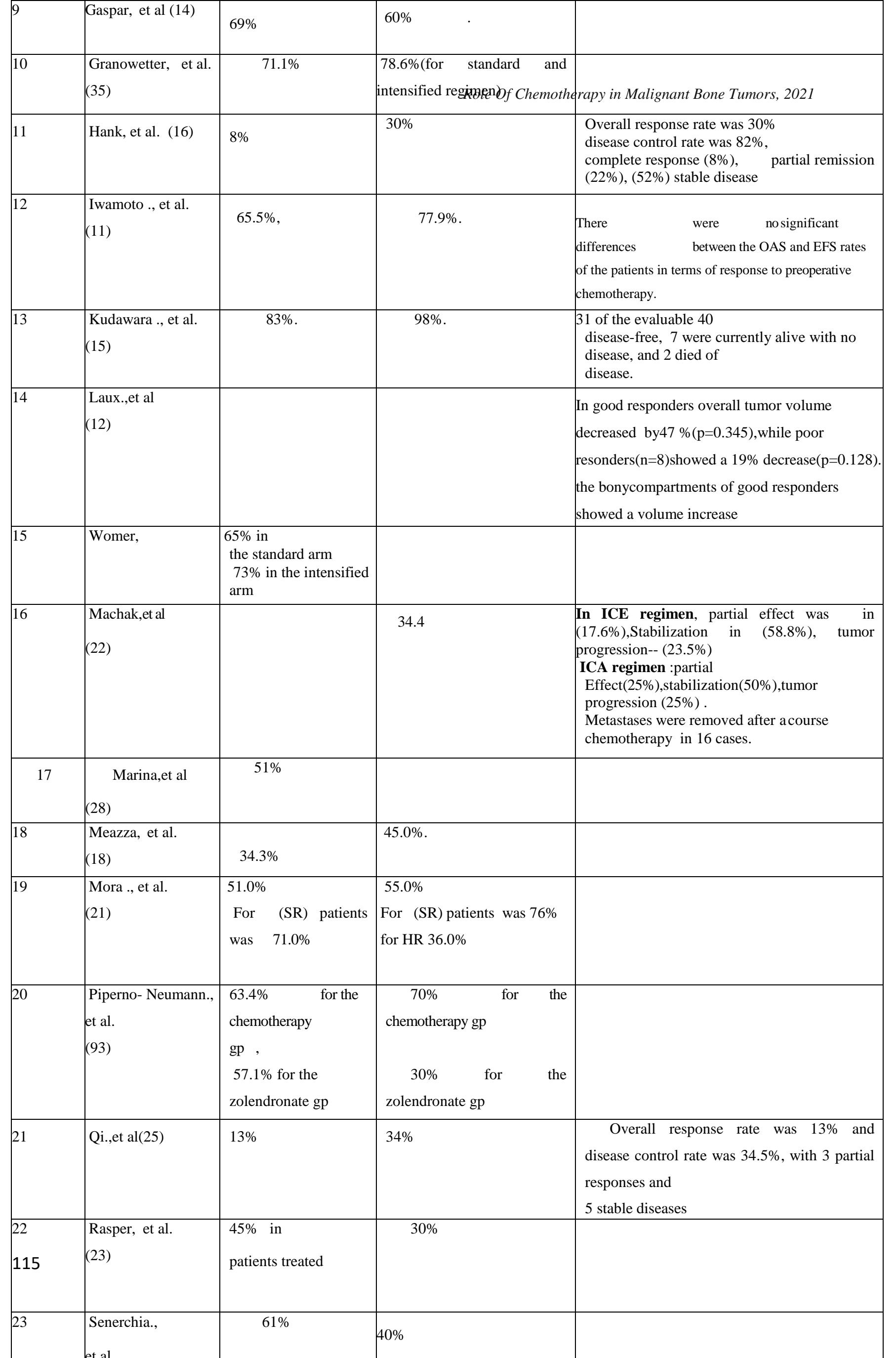




\section{Discussion}

Patients with high-grade, localized

combination with anthracycline-based osteosarcoma who received adjuvant chemotherapy after undergoing definitive surgical resection had a statistically significant benefit in disease-free and overall survival that was maintained through 25 years. Tumor necrosis after just 1 cycle of neoadjuvant chemotherapy and radiation was predictive of overall survival and disease-free survival in patients who received adjuvant chemotherapy (3).

According to Boye et al., the administration of high-dose chemotherapy with stem cell rescue was feasible, but associated with significant toxicity. Patient outcome seemed comparable to previous studies using conventional chemotherapy. They concluded that HDCT with carboplatin and etoposide should not be further explored as a treatment strategy in high-risk osteosarcoma [16 ].

Despite intensive chemotherapy plus trastuzumab for patients with HER2-positive disease In a study done by Ebb et al., the outcome for all patients was poor, with no significant difference between the HER2positive and HER2-negative groups. Although their findings suggested that trastuzumab can be safely delivered in

chemotherapy and dexrazoxane, its therapeutic benefit remains uncertain. [9].

In patients over 40 years of age with primary high-grade osteosarcoma, Ferrari et al., reported that an aggressive approach with chemotherapy and surgery can offer the probability of survival similar to that achieved in younger patients. Chemotherapy-related toxicity is significant and generally higher than that reported in younger cohorts of osteosarcoma patients treated with more intensive regimens [15].

Iwamoto and colleagues analyzed the results of the intensive neoadjuvant chemotherapy andtheeffectsofaddingIFOonpatientswithoste osarcomainJapan. Theresultssuggested efficacy of the high-dose IFO addition to the standard three-drug chemotherapy regimen. [11].

An Italian sarcoma group trial reported that neoadjuvant chemotherapy with methotrexate, cisplatin, and doxorubicin with or without ifosfamide is effective in non-metastatic osteosarcoma of the extremity. 
IFO added to MTX, CDP, and ADM from the preoperative phase does not improve the good responder rate and increases hematologic toxicity. They mentioned that IFO should only be considered in patients who have a poor histological response to MTX, CDP, and ADM [12].

According to Snerchia study,et al., EFS with MAP plus MC is not statistically superior to EFS with MAP alone in patients with high-grade, resectable OSTs of the extremities [11]

Gaspar et al., results on Ewing sarcomas showed a potential benefit of a consolidation strategy including busulfan/melphalan as compared to conventional chemotherapy and they needed confirmation by a randomized trial. [14]

This was done by Choy et al., which was the first reporter of a prospective phase II trial to evaluate the safety and efficacy of a PARP inhibitor in patients with advanced ES after failure of standard chemotherapy .Olaparib administration was safe and well tolerated when administered to this small heavily pre-treated cohort at the $400 \mathrm{mg}$ BID dose, although the median duration of dosing was for only 5.7 weeks. No significant responses or durable disease control was seen, and the short average interval to disease progression underscores the aggressiveness of this disease. Other studies to combine cytotoxic chemotherapy with PARP inhibition in EWS are actively ongoing [15].

According to Hank,et al.,a CTX-HCPT regimen can control disease progression effectively and the side effects can be tolerable for Chinese advanced Ewing's sarcoma patients. But they recommended further assessment to confirm the safety and efficacy of this treatment [15)

For localized Ewing sarcoma, Womer and colleages reported that chemotherapy administered every 2 weeks is more effective than chemotherapy administered every 3 weeks, with no increase in toxicity [14].

In another study, high-dose therapy added to the VACA-IE regimen in PR patients is feasible and effective. Selected groups of patients with ES can benefit from HDT [19].

ECT (Electrochemotherapy) should be considered a new feasible tool in the treatment of bone metastases in place or in combination with standard treatments; further developments are required to extend the use of this technique to spine metastases[16]. 


\section{Summary and conclusion.}

For newly diagnosed OS in $<40$ ys pts, neoadjuvant H.D.IFO+ADM+CDDP +surgery + adjuvant chemo (H.D.M.T), is associated with very good results (the 5 year event free survival rate is $83 \%$, the 5 year overall survival rate is $98 \%$ )

In high grade osteosarcoma adding IFO to MTX, CDP, and ADM from the preoperative phase does not improve the good responder rate and increases hematologic toxicity. IFO should only be considered in patients who have a poor histologic response to MTX, CDP, and ADM

Patients with high-grade, localized osteosarcoma who received adjuvant chemotherapy after undergoing definitive surgical resection had a statistically significant benefit in disease-free and overall survival that was maintained through 25 years. Tumor necrosis after just 1 cycle of neoadjuvant chemotherapy and radiation was predictive of overall survival and disease-free survival in patients who received adjuvant chemotherapy.

In patients over 40 years of age with primary high-grade osteosarcoma, an aggressive approach with chemotherapy and surgery can offer the probability of survival similar to that achieved in younger patients. Chemotherapy-related toxicity is significant and generally higher than that reported in younger cohorts of osteosarcoma patients treated with more intensive regimens.

For Ewing sarcoma the use of neoadjuvant VACAc/IE regimen was associated with good results $(70 \%$ event free survival rate, $75 \%$ overall survival rate)

Also Ewings sarcomas showed a potential benefit of a consolidation strategy including busulfan/melphalan as compared to conventional chemotherapy and associated with good outcome

For bone metastasis ECT may represent an active and safe treatment to achieve local control in advanced STS patients with symptomatic disease. Future research challenges include the improvement of electrode placement and voltage delivery together with the containment of soft tissue toxicity.

\section{References}

1. Siegel RL,Miller K.D, and Jemal A.Cancer statistics,CA Cancer J Clin, 2018. 68(1): p.7-30.

2. van Riel, Lesley Storey, Lorna A. Fern, 2 Ana Martins, 2 Mary Wells, 3 Lindsey Bennister, et al., Self-perception and quality of life in 
adolescents during treatment for a primary malignant bone tumour. Eur J OncolNurs, 2014. 18(3): p. 267-72.

3. Laux CJ1, Berzaczy G, Weber M, Lang S, Dominkus M, Windhager R.et al, Tumour response of osteosarcoma to neoadjuvant chemotherapy evaluated by magnetic resonance imaging as prognostic factor for outcome. Int Orthop. 2015 Jan;39(1):97-104.

4. Gibbs, C.P., Jr., K. Weber, and M.T. Scarborough, Malignant bone tumors. Instr Course Lect, 2002. 51: p.413-28.

5. Bernthal, N.M., Federman N, Eilber FR, Nelson SD, Eckardt JJ, Eilber FC,et al., Long-term results (>25 years) of a randomized, prospective clinical trial evaluating chemotherapy in patients with high-grade, operable osteosarcoma. Cancer, 2012. 118(23): p.5888-93.

6. Boye K1, Del Prever AB, Eriksson M, Saeter G, Tienghi A, Lindholm P., et al., High-dose chemotherapy with stem cell rescue in the primary treatment of metastatic and pelvic osteosarcoma: final results of the ISG/SSG II study. Pediatr Blood Cancer, 2014. 61(5): p.840-5.

7. Ebb D1, Meyers P, Grier H, Bernstein M, Gorlick R, Lipshultz SE., et al., Phase II trial of trastuzumab in combination with cytotoxic chemotherapy for treatment of metastatic osteosarcoma with human epidermal growth factor receptor 2 overexpression: a report from the children's oncology group. J ClinOncol, 2012. 30(20): p.2545-51.

8. Comandone A, Bertulli R, Bisogno G, Palmerini E, Alberghini M, Parafioriti A., et al., EUROB.O.S.S.: A European study on chemotherapy in bone-sarcoma patients aged over 40: Outcome in primary high-grade osteosarcoma. Tumori, 2018. 104(1): p.30-36.

9. Delpech Y1, Coutant C, Hsu L, Barranger E, Iwamoto T, Barcenas CH,et al., Multiinstitutional phase II study of neoadjuvant chemotherapy forosteosarcoma(NECOstudy)inJapan:NECO-

93JandNECO-95J.JOrthopSci, $2009 . \quad$ 14(4): p.397-404.

10. Ferrari S1, Ruggieri P, Cefalo G, Tamburini A, Capanna R, Fagioli F., et al., Neoadjuvant chemotherapy with methotrexate, cisplatin, and doxorubicin with or without ifosfamide in nonmetastatic osteosarcoma of the extremity: an Italian sarcoma group trial ISG/OS-1. J ClinOncol, 2012. 30(17): p. 2112-8.

11. Senerchia AA, Macedo CR1, Ferman S2, Scopinaro M3, Cacciavillano W3, BoldriniE,etal.,Resultsofarandomized,prospective clinicaltrialevaluating metronomic chemotherapy in nonmetastatic patients with high-grade, operable osteosarcomas of the extremities: A report from the Latin American Group of Osteosarcoma Treatment. Cancer, 2017. 123(6): p.1003-1010.

12. Gaspar N1, Rey A, Bérard PM, Michon J, Gentet JC, Tabone MD,et al., Risk adapted chemotherapy for localised Ewing's sarcoma of bone: the French EW93 study. Eur J Cancer, 2012. 48(9): p.1376-85.

13. Han K1, Sun Y, Zhang J, He A, Zheng S, Shen Z, et al., Cyclophosphamide-hydroxycamptothecin as second-line chemotherapy for advanced Ewing's sarcoma: experience of a single institution. Asia Pac J ClinOncol, 2014. 10(2): p.e114-7.

14.Womer RB1, West DC, Krailo MD, Dickman PS, Pawel BR, Grier HE., et al., Randomized 
controlled trial of interval-compressed chemotherapy for the treatment of localized ClinOncol, 2012. 30(33): p.4148-54.

15. Ferrari,S.,etal.,NonmetastaticEwingfamilytu mors:high-dosechemotherapywith stem cell rescue in poor responder patients. Results of the Italian SarcomaGroup/ScandinavianSarcomaGroupIIIproto col.AnnOncol,2011.22(5):p.1221- 7.

16. Campana LG1, Bianchi G, Mocellin S, Valpione S, Campanacci L, Brunello A,et al., Electrochemotherapy in the Treatment of Bone Metastases: A Phase II Trial. World J Surg, 2016. 40(12): p.3088-3094.

17. Granowetter L1, Womer R, Devidas M, Krailo M, Wang C, Bernstein M., et al., Dose-intensified compared with standard chemotherapy for nonmetastatic Ewing sarcoma family of tumors: Children's Oncology Group Study. J ClinOncol, 2009. 27(15): p.2536-41.
Ewing sarcoma: a report from the Children's Oncology Group. J

18. Mora J1, Castañeda A1, Perez-Jaume S1, LopezPousa A2, Maradiegue E1, Valverde C, et al., GEIS-21: a multicentric phase II study of intensive chemotherapy including gemcitabine and docetaxel for the treatment of Ewing sarcoma of children and adults: a report from the Spanish sarcoma group (GEIS). $\mathrm{Br} \mathrm{J}$ Cancer, 2017. 117(6): p. 767-774.

19. Rasper M1, Jabar S, Ranft A, Jürgens H, Amler $\mathrm{S}$, Dirksen U.,et al., The value of high-dose chemotherapy in patients with first relapsed Ewing sarcoma. Pediatr Blood Cancer, 2014. 61(8): p.1382-6.

To cite this article: George Romany, Galal El Din Kazem, Mohamed A. Meselhy, Mahmoud I. Kandil. Role of Chemotherapy in Malignant Bone Tumors. BMFJ 2021; 38 (orthopedic surgery): 108-120. DOI: 10.21608/bmfj.2021.21014.1190 